\title{
Study on Manufacturing Process and Current Carrying Characteristics of Layering Enamelled Stranded Conductor
}

\author{
Shijie Xiao ${ }^{1}$, Zhenxing Jiang ${ }^{2}$, Liming Yang ${ }^{2}$, Xinlun Zhang ${ }^{2}$, Wenjie Mei $^{3}$, Zhongjian Wang ${ }^{2}$ \\ ${ }^{1}$ State Grid Zhejiang Electric Power Company, LTD, Hangzhou, 310007, Zhejiang, China \\ ${ }^{2}$ NARI Group Corporation (State Grid Electric Power Research Institute), 211000, Nanjing, Jiangsu, China \\ ${ }^{3}$ Hengtong Submarine Power Cable Department of Research and Development Co., Ltd, 215537, Jiangsu Province, China
}

\begin{abstract}
Ultra high voltage(UHV) power cable system is an economical, safe and reliable power transmission mode. In recent years, the concern about the traditional fossil energy pollution in the world and the determination to using clean energy have promote the medium distance UHV submarine power cable system. This paper designs and tests one kind of energy saving and loss reducing conductor applied to large cross-section submarine cable. Through reasonable process control, the paint film on the enamelled wire surface can be avoided being scraped during the process of twisting. According to the measured AC / DC resistance ratio, the optimized design for the subsequent conductor is put forward. Compared with the traditional conductor, the current carrying capacity of the conductor is improved, and it has a positive and practical significance for reducing the Joule loss of the cable system.
\end{abstract}

\section{Introduction}

With the rapid growth of energy consumption demand, the inhomogeneous distribution of the existing global energy resources is becoming more and more serious, which has caused the shortage of electricity supply in many regions, especially the island countries. The engineering application of large length ultra-high pressure cross-linked polyethylene insulated (XLPE) submarine cable technology can not only eliminate the marine leakage of the oil filled cable and protect the anxiety of the forest, but also have the advantages of environmental protection, high reliability and low cost.

As an important part of the cable, the cable conductor plays the role of carrying the current. The heat generated during its operation occupies the main part of the whole cable heating. Some experts and scholars at home and abroad have studied the cable conductors of different structures[1], including the bare copper monofilament twisted conductor, the copper oxide single conductor, the enameled single wire twisted conductor, the insulated paper layer around the wrapping conductor and so on. At the same time, the AC resistance calculation and testing technology of large cross section conductors is one of the hotspots of research[2][3][4][5][6][7][8] at home and abroad, but at present, there are no practical and insulation compatibility conductors. This paper presents a new type of energy saving and loss reducing conductor compatible with three classical structures of internal shielding, insulation and shielding. The conductor sample has been manufactured, which effectively increases the effective cross-sectional area of the conductor and improves the current carrying capacity.

\section{Structure design of layering enamelled stranded conductor}

The conductor is designed for long distance large cross section submarine cables. In view of the difficulty in the storage of the semi-finished products of the large section conductor and the difficulty in the assembly of the segmented segments of the large length divided conductors, the circular compact conductor has a better advantage [9][10][11] than the divided conductor in this application scene. As conductor resistance increases linearly with length, reducing conductor resistance has considerable effect on increasing the current carrying capacity of cables. In this paper, a layer of enamelled insulated circular compact conductor is designed. The conductor can be named as layering enameled stranded conductor(LESC), and the normal one can be named as copper wire stranded conductor(CWSC). Taking 1800 square millimetre section area as an example, two design schemes are adopted, and the structure is shown in Fig. 1 and Fig. 2.

The conductor adopts circular tight pressure form, and the single line is annealed naked round copper wire and round enamelled wire. Each layer should be composed of single bare copper wire or enamelled wire, the bare copper wire layer and enamelled wire layer are intersecting, and the center and outer layer of the 
conductor should be bare copper wire, and the diameter of all bare copper wire and enamelled wire is 4 millimetre. In order to follow the permeation test of conductors, a layer of PE insulation sleeves is finished as conductor of finished conductors. The number of single line of the conductor and the diameter Table 1 and Table 2 are shown.

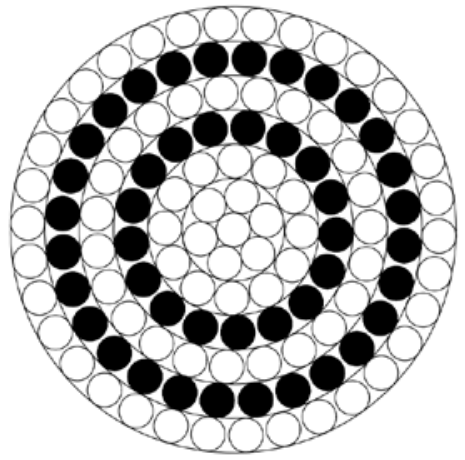

Figure 1. Structure diagram of the conductor of the scheme a

Table 1. Single line root number and diameter of each layer of conductor with scheme a

\begin{tabular}{|c|c|c|c|c|}
\hline $\begin{array}{c}\text { Serial } \\
\text { number }\end{array}$ & Single wire & $\begin{array}{c}\text { Wire } \\
\text { diameter/m } \\
\mathbf{m}\end{array}$ & $\begin{array}{c}\text { Root } \\
\text { number/ } \\
\text { mm }\end{array}$ & $\begin{array}{c}\text { Tightened } \\
\text { external } \\
\text { diameter/m } \\
\text { m }\end{array}$ \\
\hline $\begin{array}{c}\text { Central } \\
\text { layer }\end{array}$ & Copper wire & 4.47 & $1+6$ & 12.2 \\
\hline $\begin{array}{c}\text { Second } \\
\text { stranded } \\
\text { layer }\end{array}$ & Copper wire & 4.40 & 12 & 21.1 \\
\hline $\begin{array}{l}\text { Third } \\
\text { stranded } \\
\text { layer }\end{array}$ & $\begin{array}{l}\text { enamelled } \\
\text { wire }\end{array}$ & 4.47 & 17 & 30.3 \\
\hline $\begin{array}{c}\text { Fourth } \\
\text { stranded } \\
\text { layer }\end{array}$ & Copper wire & 4.40 & 22 & 38.1 \\
\hline $\begin{array}{c}\text { Fifth } \\
\text { stranded } \\
\text { layer }\end{array}$ & $\begin{array}{l}\text { enamelled } \\
\text { wire }\end{array}$ & 4.47 & 28 & 45.3 \\
\hline $\begin{array}{l}\text { Sixth } \\
\text { stranded } \\
\text { layer }\end{array}$ & Copper wire & 4.40 & 32 & 50.5 \\
\hline
\end{tabular}

Table 2. Single line root number and diameter of each layer of conductor with scheme b

\begin{tabular}{|c|c|c|c|c|}
\hline $\begin{array}{c}\text { Serial } \\
\text { number }\end{array}$ & Single wire & $\begin{array}{c}\text { Wire } \\
\text { diameter/m } \\
\mathbf{m}\end{array}$ & $\begin{array}{c}\text { Root } \\
\text { number/ } \\
\mathbf{m m}\end{array}$ & $\begin{array}{c}\text { Tightened } \\
\text { external } \\
\text { diameter/m } \\
\mathbf{m}\end{array}$ \\
\hline $\begin{array}{c}\text { Central } \\
\text { layer }\end{array}$ & Copper wire & 4.0 & $1+6$ & 10.2 \\
\hline $\begin{array}{c}\text { Second } \\
\text { stranded } \\
\text { layer }\end{array}$ & $\begin{array}{c}\text { enamelled } \\
\text { wire }\end{array}$ & 4.0 & 12 & 17.2 \\
\hline $\begin{array}{c}\text { Third } \\
\text { stranded } \\
\text { layer }\end{array}$ & Copper wire & 4.0 & 17 & 24.0 \\
\hline $\begin{array}{c}\text { Fourth } \\
\text { stranded } \\
\text { layer }\end{array}$ & enamelled & 4.0 & 22 & 31.1 \\
\hline $\begin{array}{c}\text { Fifth } \\
\text { stranded } \\
\text { layer }\end{array}$ & Copper wire & 4.0 & 28 & 37.6 \\
\hline
\end{tabular}

\begin{tabular}{|c|c|c|c|c|}
\hline $\begin{array}{c}\text { Sixth } \\
\text { stranded } \\
\text { layer }\end{array}$ & $\begin{array}{c}\text { enamelled } \\
\text { wire }\end{array}$ & 4.0 & 32 & 44.6 \\
\hline $\begin{array}{c}\text { Seventh } \\
\text { stranded } \\
\text { layer }\end{array}$ & Copper wire & 4.0 & 37 & 51.5 \\
\hline
\end{tabular}

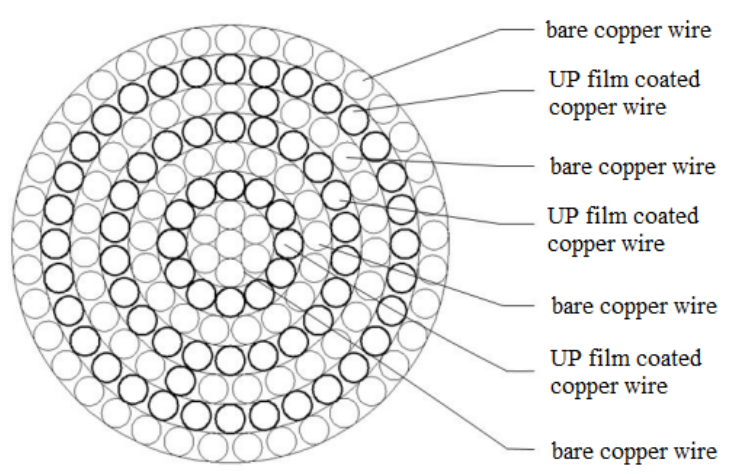

Figure 2. Structure diagram of the conductor of the scheme b

\section{Production Process of Conductor}

According to GB/T 3956-2008 "conductor of cable"[12], the maximum resistance of 1800 square millimetre copper conductor at 20 Centigrade should not be more than 0.0101 omega per kilometre. The actual section area is fully satisfied with the electrical performance when 1800 square millimetre is calculated theoretically. When the soft copper wire is tightened and pressed, the section reduction ratio is large, and the compactness coefficient is designed to be 0.93 . The total cross-sectional area of all round copper wires should be 1935 square millimetre before pressing.

In the stranding process, the joint is welded by resistance. The distance between any two joints on the same single line or whole wire is not less than 15 meter. For the ratio of pitch to diameter, the ratio of pitch to diameter of any layer is not greater than that of the adjacent inner layer. Dies coated with nanomaterials is adopted for the compact die, the tolerance is +0.50 millimetre. The nylon die can be used for the wire die, and the size of the die hole should be smaller than that of the wire diameter $-0.9 \sim 0$ millimetre. The DC resistance of conductor at 20 Centigrade is not greater than 0.0101 per kilometre.

A layer of water blocking tape is used to wrap around each layer of the conductor. The overlap rate of the wrapping is not less than five percent, but not more than 20 percent. When the overlap rate is met, the smaller the overlap rate is, the better. The field stranding diagram of bare copper single layer and enameled wire is shown in Fig. 3. The surface state of the enameled wire after stranding is shown in Fig. 4. It can be seen from the diagram that the surface of the enameled wire layer is smooth, burr free and film damaged after tight compression. At the same time, the inner and outer layers also wrap around the semi conductive resistance water zone. Fig. 5 shows the sample diagram of a good laminated enameled stranded conductor. 

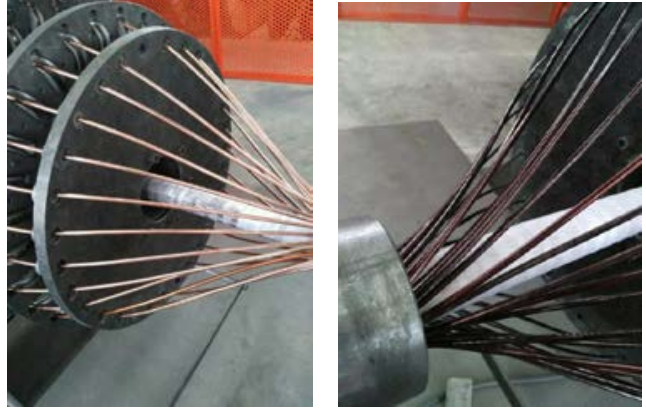

Figure 3. Field stranding picture of copper wire and enamelled wire

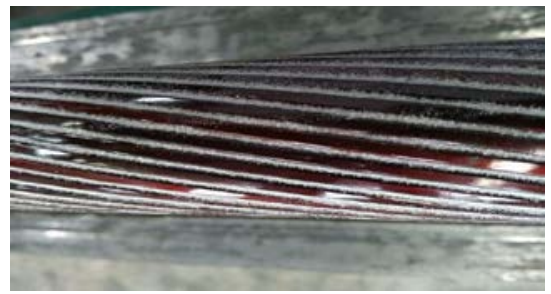

Figure 4. Surface photo of enamelled wire layer

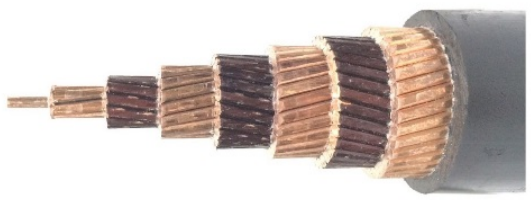

Figure 5. Sample drawing of layered enameled stranded conductor

\section{Test of Conductor AC Resistance}

In this paper, AC resistance tester is used to test the AC resistance of bare copper monofilament stranded conductors and layered enameled insulated stranded conductors. The test is based on the four terminal method. When testing, wrap a layer of insulating tape outside the conductor and wrap it with a grounding copper strap to shield the external interference and improve the accuracy of the test.

Table 3 shows the AC resistance and AC / DC resistance ratio of the enameled insulated conductor and bare copper conductor manufactured by the two trial.

Table 3. Test results of AC resistance of two trial conductors

\begin{tabular}{|c|c|c|c|c|}
\hline $\begin{array}{c}\text { Serial } \\
\text { number }\end{array}$ & Scheme & Sample type & $\begin{array}{c}\text { AC / DC } \\
\text { resistance } \\
\text { ratio }\end{array}$ & $\begin{array}{c}\text { AC } \\
\text { resistance } \\
(\text { omega } \\
/ \mathbf{k m})\end{array}$ \\
\hline One & \multirow{2}{*}{ a } & LESC & 1.294 & 0.0131 \\
\hline Two & & CWSC & 1.396 & 0.0141 \\
\hline Three & \multirow{2}{*}{ b } & LESC & 1.118 & 0.0113 \\
\hline Four & & CWSC & 1.329 & 0.0134 \\
\hline
\end{tabular}

The AC resistance test data shows that the $\mathrm{AC}$ resistance of the scheme a is a little higher than that of the scheme $b$, but the differences is monofilament diameter of scheme $b$ is smaller and the total number of the monofilament is more.

\section{Calculation of Current Carrying Characteristics of Conductors}

The carrying capacity is based on the design of the 500 kilovolt submarine cable in Zhoushan and the mainland interconnection project. The carrying capacity is 1270 ampere and the room temperature is 30 Centigrade. According to the Joule heating formula $\mathrm{P}=\mathrm{I}^{2} \mathrm{R}$, the Joule heat loss of 18 kilometer long enameled insulated conductor and bare copper conductor at full load is calculated as shown in Table 4.

Table 4. Loss calculation of $1800 \mathrm{~mm}^{2}$ and 18 kilometer long conductor at rated current 1270 ampere

\begin{tabular}{|c|c|c|c|c|}
\hline \multirow{2}{*}{$\begin{array}{c}\text { Serial } \\
\text { number }\end{array}$} & \multirow{2}{*}{ Scheme } & \multicolumn{2}{|c|}{ Joule heat loss(kW) } & \multirow{2}{*}{$\begin{array}{c}\text { Joule heat } \\
\text { loss } \\
\text { percentage } \\
/(\%)\end{array}$} \\
\cline { 3 - 4 } & CWSC & LESC & 7.09 \\
\hline One & a & 409.35 & 380.32 & 75.67 \\
\hline Two & b & 389.03 & 328.06 & 15 \\
\hline
\end{tabular}

The temperature rise of the conductor can be calculated by the formula of the overhead line carrying capacity[13]. According to the formula (1), according to the formula (2) in the first book of the second edition of the wire and cable manual, the calculation formula of the overhead wire in the bare conductor and the bare conductor in the case of no wind and no sunshine in the bare conductor products is shown as formula (1) :

$$
I=\sqrt{\left(W_{R}+W_{N}\right) / R_{a c}}
$$

Calculation of radiation power $\mathrm{W}_{\mathrm{R}}$ is show in formula (2):

$$
W_{R}=\pi D E_{1} S_{1} \cdot\left[\left(\theta+\theta_{a}+273\right)^{4}-\left(\theta_{a}+273\right)^{4}\right]
$$

In this formula:

$\Pi$ : orchards, 3.14;

$D$ : wire diameter (meter);

$E_{1}$ : radiant heat dissipation coefficient of wire surface to bright new line $0.23 \sim 0.43$. For old line or black preservative line $0.90 \sim 0.95$, the calculated value is 0.43 ;

$\mathrm{S}_{1}$ : Stephen Boltzmann constant, $v=5.67 \times 10^{-8}$ (watt per meter squared);

$\theta$ : the average temperature rise on the surface of a wire, (Centigrade) ;

$\theta_{\mathrm{a}}$ : ambient temperature, (Centigrade) ;

$\theta+\theta_{\mathrm{a}}$ : conductor allowable maximum temperature (Centigrade).

The natural air convection heat dissipation power $\mathrm{W}_{\mathrm{N}}$ is calculated as follows:

When $10^{-4}<<\mathrm{D}^{3} \theta<10^{-2}$, the formula is calculated by formula (3).

$$
\mathrm{W}_{\mathrm{N}}=4.585 \cdot \theta\left(\mathrm{D}^{3} \theta\right)^{0.27}
$$


When $10^{-6}<<\mathrm{D}^{3} \cdot \theta<10^{-4}$, the formula is calculated by formula (4).

$$
\mathrm{W}_{\mathrm{N}}=3.165 \cdot \theta(\mathrm{D} 3 \theta)^{0.23}
$$

Calculation of the AC resistance Rac (t) of the running wire is shown in formula (5):

$$
R_{a c(t)}=(1+k) \times R_{20} \times\left(1+\alpha_{20} \times\left(\theta+\theta_{a}-20\right)\right)
$$

The temperature of the layered enameled conductor and bare copper conductor is calculated and the difference between them is calculated, as shown in Table 5.

Table 5. Calculation results of temperature rise of LESC and CWSC

\begin{tabular}{|c|c|c|c|c|}
\hline Scheme & $\begin{array}{c}\text { Temper- } \\
\text { ature of } \\
\text { CWSC }\end{array}$ & $\begin{array}{c}\text { Temperat- } \\
\text { ure of } \\
\text { LESC }\end{array}$ & $\begin{array}{c}\text { Tempera- } \\
\text { ture } \\
\text { reduction }\end{array}$ & $\begin{array}{c}\text { Percentage } \\
\text { of } \\
\text { temperature } \\
\text { reduction }\end{array}$ \\
\hline $\mathrm{a}$ & 62.2 & 61.0 & 1.2 & 1.92 \\
\hline $\mathrm{b}$ & 61.4 & 59.0 & 2.4 & 3.91 \\
\hline
\end{tabular}

\section{Water Penetration Test}

The conductor designed in this paper is used for the largest submarine cable laying the sea depth 100 meter. The corresponding pressure is 1 megapascal. Therefore, the longitudinal water resistance of the cable conductor must be examined in the deep water so as to ensure the longitudinal osmosis distance of the submarine cable after the insulation damaged sea water penetrated into the conductor, which will affect the failure of the submarine cable. The length of abandonment is not conducive to the repair of submarine cables in case of failure.

\subsection{Test Method}

After the conductor is transported to the test room, the conductor of the conductor of 6 meter is stripped out of the conductor of 50 millimeter from one end. It is used as a pressurized end. It is sealed and waterproof with high pressure waterproof self adhesive tape. The sealing ring is stuck through the flange and top cover, and the sealing flange and pressure bin are fixed with bolt nuts. At the same time, three percent of the strong brine was added to the deep water pressurized chamber, and then the pressure was applied to the pressurized chamber through the pressure system, and the water pressure of the 1 megapascal was maintained for 10 days according to the standard GB/T 31489.1-2015[14]. After the experiment started, the water pressure was continuously added for 10 days, and the water pressure was recorded 1 hours a day, such as the water pressure was reduced by water, and the pressure was filled in time with manual pressure pump.

\subsection{Test Result}

After 10 days of water pressure, water pressure is lowered and the water is released from the pressure vessel. Saw the sample from the middle to see if there is any water mark, and then judge the position of the permeability point according to the observation results. If there is no water at the first breakpoint, second middle saws near the pressure end are found. If there is water at the first breakpoint, the intermediate saw far away from the pressure end is second times, and the analogous step is progressively approaching the permeable point. The distance between the farthest point of permeability and the pressure end is 3.3 meter, which is near the position of 3 in Fig. 6. The cross-sectional anatomy and location of each point are shown in Fig. 6.

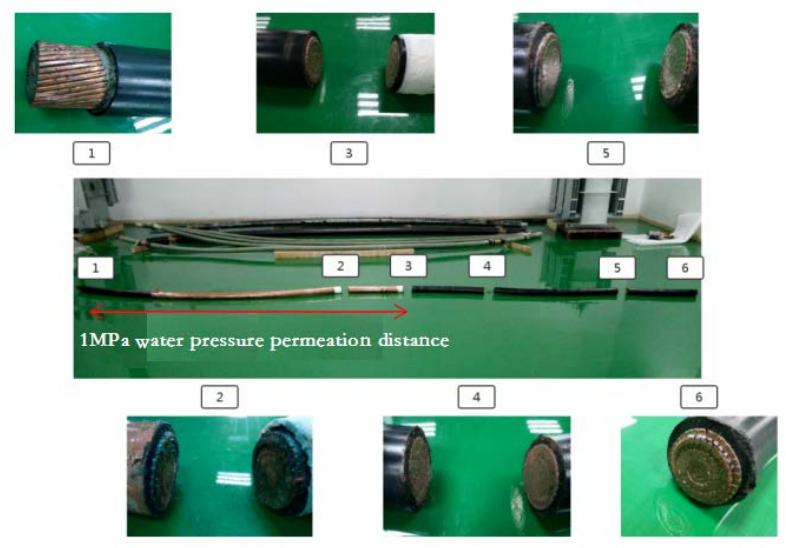

Figure 6. Schematic diagram of the results of water penetration test

\section{Conclusion}

1. When the design and trial manufacture of LESCs are made, the thinner strands will be selected to reduce the AC / DC resistance ratio of conductors.

2. The trial made LESCs can reduce Joule heat loss by 15 percent and reduce conductor surface temperature by 3.9 percent when applied.

3. The conductor adopts a circular compressed layer enameled insulated structure, which has a very short penetration distance while reducing AC resistance.

\section{Acknowledgement}

The research work of this paper is funded by the State Grid Corporation science and technology project (5211DS17002F) and is strongly supported by the research team of Professor Wu Weining of NARI Technology Co., Ltd. Thanks for the conductor samples provided by NARI Yinlong Cable Co., Ltd and Hengtong Submarine Power Cable Co.,Ltd. and so on. I hereby express my deep appreciation.

\section{Reference}

1. CIGRE WORKING GROUP B1.03 272 Large Cross-sections and composite screens design. (2005).

2. K. Sugiyama u. a. "The skin effect of large size conductors for power cables", Conf. IEEJ Tokyo Branch. 6. (1977). 
3. Liu, Bao. "Design and Manufacture of Large Size Segmental Conductors." Electric Wire \& Cable (2005).

4. K. Sugiyama. "Development of inter-layer insulated segmental conductor with low skin effect for power cables". Elect. Eng. Jpn. 101.6, 98-108 (1981).

5. V.T. Morgan, R.D. Findlay and S. Derrah, "New formula to calculate the skin effect in isolated tubular conductors at low frequencies", Science, Measurement and Technology, IEE Proceedings. Jul. 147.4, 169-171 (2000).

6. E. H. Salter, "Problems in the Measurement of A-C Resistance and Reactance of Large Conductors". American Institute of Electrical Engineers, Transactions of the 67.2 .Jan. 1390-1397 (1948).

7. DENG Xianbo, OUYANG Benhong, KONG Xianghai, et al. "optimization of AC resistance of large cross-section high-voltage cable conductor". High Voltage Engineering, 42.2 :522-527 (2016).

8. P. Argaut and J.Y. Daurelle, "Calculation method of power cables AC resistance with individually insulated strands", Proc. of Jicable'99. Bd. 2. Versailles, France, Jun. 582-591 (1999).
9. Jiang Zhen Xing. "1600mm2 undivided composite wrought aluminum alloy cable conductor development." China's new technology and new products 2: 56-57 (2018).

10. Zhang, Hongliang, et al. "Design and Test Verification of China's First $\pm 525 \mathrm{kV}$ XLPE Insulated DC Cable." Southern Power System Technology (2018).

11. Mei Wenjie, et al. "Design of high voltage DC submarine cable shaped compact single conductor circular compact conductor." optical fiber and cable and its application technology 6: 13-15 (2016).

12. Conductor of cables: GB /T 3956 - 2008 (2th ed.). Beijing, China: China Standard Press (2008).

13. Wire and cable Handbook (2th ed.). Beijing, China: China Machine Press (2002).

14. D.C. extruded cable systems for power transmission at a rated voltage up to and including $500 \mathrm{kV}$ - Part 1 : Test methods and requirements: GB /T 3956 - 2008 (1th ed.). Beijing, China: China Standard Press (2015). 